\title{
Understanding recycling behavior: a study of motivational factors behind waste recycling
}

\author{
K. Johansson \\ Department of Design Sciences, Lund University, Sweden
}

\begin{abstract}
Globally, waste volumes are increasing rapidly and the World Bank estimates a $70 \%$ global increase in municipal solid waste up to 2025 . Waste may have serious environmental consequences and there is a strong correlation between solid waste generation rates and greenhouse gas emissions. These two observations alone indicate that this development is not sustainable. Recycling is one of the most important actions currently available to reduce the environmental impact of waste. While, waste recycling in OECD countries is reported to be approximately $22 \%$ on average, many developing countries have recycling rates in the range of $1-3 \%$. A key aspect in succeeding with any recycling effort is how authorities and other actors relate to both informal and formal waste workers. This paper reports on the findings of a systematic literature study with the aim of exploring waste recycling behavior, with a special focus on motivational factors, both physical and psychological, behind recycling. Three levels of descending importance for recycling have been identified, where two are vital for success, and the third is desirable; 1) a well-designed infrastructure for recycling 2) specific recycling knowledge, and, 3) a general understanding of environmental aspects. Any attempt to implement or improve recycling systems and/or recycling behavior, needs to consider these aspects and the insights gained through this research may provide decision makers with practical assistance. The paper also contributes by providing academia with a framework for further studies on the behavioral aspects of recycling.

Keywords: behavior, motivational factors, recycling, waste management.
\end{abstract}




\section{Introduction}

Waste can be both a problem and an asset. If waste is not taken care of properly, it can harm both people and the environment. Consequently, waste should be recovered as much as possible, either as material, humus and nutrients or energy. Waste can thus be seen as an important resource. Taking into account the growing population, which in just over ten years between 1999 and 2011 increased by 1 billion people and reached 7 billion people (UN 2015) and is estimated to be 9.7 billion by 2050, the increasing of industrialization and urbanization [1] man can no longer afford to manage waste as waste, but has to use it as a resource.

"The Tragedy of the Commons" stems from Garrett Hardin's article from 1968 in which he referred to a resource which is owned by no one and but everyone has access to [2]. This means both taking too much from a common resource, but also putting too much into it. Hardin stated that "in a reverse way, the tragedy of the commons reappears in problems of pollution". He believed that in order to avoid destruction, humans would have to change their values and ideas of morality [3]. For many years the public concern for environmental protection and sustainable development has been genuine, but despite this unsustainable development trends persist [4]. For example, the quantity of municipal solid waste is expected to reach 2.2 billion tons per year by 2025, and even if countries like Cambodia, Algeria and Morocco collect more than $70 \%$ of urban waste, more than $95 \%$ of it is dumped in landfills or elsewhere without further treatment [5]. However, the recycling trends in some western countries are beginning to reach relatively high levels [6]. The increasing urbanization in the developing world, will accentuate the waste problem and the need to recycle. For example, in greater Shanghai, there are now over 23 million people, and in their household waste they leave $60-70 \%$ of food waste components [7]. There is clearly a dire need to remove this part of the waste stream and to convert it into useful resources such as biogas and/or compost, rather than dump it in a landfill.

Waste recycling systems are often dependent on consumers' or end users' more or less voluntary labor to function, which is especially true for residential recycling [8]. For example, considerable household waste must be sorted in the home before it can be left at curbside collection points or drop-off centers. This sorting work is mainly carried out by the people in the individual household. Sometimes it even requires that people travel a short or a long distance by car to leave the sorted waste at special collection points. However, recycling is also found at people's places of work. For example, the construction industry accounts for a significant portion of the total amount of waste in the developed world and hence sorting at the workplace is crucial to optimizing waste as a useful resource.

For recycling to be successful, whether at home or at work, there are several very different aspects to consider. These are aspects such as physical features, behavioral patterns, levels of knowledge, attitudes and perceptions and the complex interrelation between them [9]. Nevertheless, also demographic characteristics and social norms matter [1] as well as incentive schemes [10], policies [11] or how mature the recycling society is [12]. 
The purpose of this paper is to explore waste recycling behavior in general, as well as to study how recycling behavior is affected by different motivational factors, both physical and psychological. The end point will be to present a model which discriminates between different recycling characters based on the results of the study.

\section{Research methodology}

This paper is based on a systematic literature study. Literature studies can describe the state of knowledge in a particular area and are suitable for answering questions of a qualitative nature, finding holes in the research field, and providing a base for future research [13-15]. A systematic literature study differs from an unsystematic literature study in the sense that the systematic study tries methodically to overcome biases in the review and content analysis processes. In order to explain the research question from a structured literature study relevant texts must be found [16].

While there has been at least one other recent literature review on the subject of waste prevention [17] this research provides a broader view of the individual recycler, whereas Wilson et al. have concentrated more on business attitudes and behaviors. There has also been a literature review on the determinants of recycling behavior [18] carried out 20 years ago. Since over $80 \%$ of the articles referenced in this paper have been written and published in the twenty years which have since passed, and the Hornik et al. [18] article adopted/was based on a quantitative appraisal, this research provides an updated picture and a more qualitative point of view. Scientific work is perishable [19] and an update of similar areas of research may be required.

Due to the inclusion and exclusion criteria, the search engine's general limitations, and common language barriers there may plausibly be other literature reviews conducted in the area which have been overlooked.

\subsection{Literature search}

To find relevant texts, the database LUBsearch was used. LUBsearch is an online database at the library at Lund University in Sweden and includes articles, journals, books and other resources, both electronic and in print. The inclusion criteria for the literature search were that only peer reviewed articles published in scientific journals, written in English with both abstracts and full texts were used. Both qualitative and quantitative articles were included in the search. Only peerreviewed material was used to guarantee the quality of the articles. The exclusion criteria were any articles written or published after completing the data search.

\subsection{Sample selection}

The keywords used for the sampling was taken from the purpose explanation of the paper; The purpose of this paper is to explore waste recycling behavior in general, as well as to study how recycling behavior is affected by different motivational factors, both physical and psychological. The end point will be to present a model which discriminates between different recycling characters based 
on the results of the study. Initially used were the words: "waste", "behavior" and "motivational", which produced 203 references, unfortunately many of them had main topics not related to waste handling, but to other matters, for example, attitudes to shopping, which had some impact on waste, but the waste issues were neither discussed nor analyzed in any greater detail. In a second search the word "recycling" was added to capture the area in a better way. More searches were done to see if it was possible to capture the area even better and words as "environment", "challenge", "sustainability" or "barrier" were added separately, but each one resulted in either too small a sample or there was only a marginal difference. Account has been taken of the differences in spelling between British and American English.

The final search resulted in 82 references from 34 different journals and seemed to cover the area satisfactorily. Several articles reappeared, however, and the number of individual articles was 76 . The number of journals was still unchanged and they could be categorized into six groups (see table 1). Some of the journals on the other hand overlapped, for example, "Journal of Environmental Psychology". In those cases the journal was filed either under environmental journals or psychological journals depending on the institution the author represented or the majority of authors represented.

Table 1: Articles by type of journal.

\begin{tabular}{lrr}
\hline Journal types & \# Journals & \# Articles \\
\hline Waste oriented journals & 11 & 45 \\
Economic or business oriented journals & 4 & 7 \\
Psychological oriented journals & 4 & 7 \\
Consumer oriented journals & 4 & 6 \\
Design and architectural oriented journals & 3 & 3 \\
Other & 8 & 8 \\
\hline Total & $\mathbf{3 4}$ & $\mathbf{7 6}$ \\
\hline
\end{tabular}

The first step in the selection was carried out as a preliminary assessment of titles and reading the abstracts. After the initial selection four articles were deemed not to fit in and removed from the study.

In the second step the articles were read through to get an overall idea of the study. A standard scorecard was used when screening the articles and the keywords of each study were identified. The aim was to identify the details, similarities, and differences in each individual study and to exclude articles not fit for the purpose. The final sample consisted of 62 studies that were considered appropriate to answering the research purpose.

The keywords were collected and covered 133 different words or combinations of words. They were divided into categories of a similar nature. The categories then formed themes to be used in the analysis. 


\section{Analysis}

All of the screened documents were sorted for relevance and categorized as inputs to the detailed analysis. The keywords of the articles were categorized into 14 larger groups. All the groups were not used in the later analysis, only those which in a broad logical sense could explain the behavior of recycling (a help or an obstacle to a desired practice). For example (as shown in table 2), different

Table 2: Articles by continent, decade and research method.

\begin{tabular}{lrrrlr}
\hline Continent & No. & Published & No. & Method & No. \\
\hline America & 23 & $70 \mathrm{~s}$ & 1 & Survey & 49 \\
Asia & 9 & $80 \mathrm{~s}$ & 1 & Interview & 10 \\
Europe & 40 & $90 \mathrm{~s}$ & 18 & Experiment & 3 \\
& & $00 \mathrm{~s}$ & 21 & Case study & 5 \\
& & $10 \mathrm{~s}$ & 31 & Literature review & 2 \\
& & & & Modeling & 2 \\
\hline Total & $\mathbf{7 2}$ & & $\mathbf{7 2}$ & & $\mathbf{7 2}$ \\
\hline
\end{tabular}

Table 3: Keyword categories.

\begin{tabular}{|c|c|c|}
\hline Name of category & Example of keywords & Comment \\
\hline Background factors & $\begin{array}{l}\text { Adolescent } \\
\text { Aging }\end{array}$ & $\begin{array}{l}\text { Included in the analysis since it } \\
\text { may impact recycling behavior. }\end{array}$ \\
\hline Behavior & $\begin{array}{l}\text { Behavior change } \\
\text { Observed behavior }\end{array}$ & $\begin{array}{l}\text { Not included in the analysis since } \\
\text { behavior is the object of this study } \\
\text { rather than an explanatory factor }\end{array}$ \\
\hline $\begin{array}{l}\text { Communication/ } \\
\text { information }\end{array}$ & $\begin{array}{l}\text { Communication strategy } \\
\text { Marketing communications }\end{array}$ & $\begin{array}{l}\text { Included in the analysis since it } \\
\text { may impact recycling behavior. }\end{array}$ \\
\hline Design & $\begin{array}{l}\text { Drop-off recycling } \\
\text { Recycling program design }\end{array}$ & $\begin{array}{l}\text { Included in the analysis since it } \\
\text { may impact recycling behavior. }\end{array}$ \\
\hline Incentives & $\begin{array}{l}\text { Willingness to pay } \\
\text { Anticipated guilt }\end{array}$ & $\begin{array}{l}\text { Included in the analysis since it may } \\
\text { impact recycling behavior. }\end{array}$ \\
\hline Location of study & $\begin{array}{l}\text { USA } \\
\text { Dublin }\end{array}$ & Not included in the analysis. \\
\hline Research method & $\begin{array}{l}\text { Case study } \\
\text { Cluster analysis }\end{array}$ & Not included in the analysis \\
\hline Subject area & $\begin{array}{l}\text { Environmental psychology } \\
\text { Environment }\end{array}$ & Not included in the analysis \\
\hline Theory & $\begin{array}{l}\text { Grounded theory } \\
\text { Self-determination theory }\end{array}$ & Not included in the analysis \\
\hline Waste categories & $\begin{array}{l}\text { Domestic waste } \\
\text { Electronic waste }\end{array}$ & $\begin{array}{l}\text { Not included in the analysis. The } \\
\text { type of waste may, however have } \\
\text { an impact, but it is not sufficiently } \\
\text { explored in the literature and } \\
\text { therefore the category is dropped. }\end{array}$ \\
\hline Other & $\begin{array}{l}\text { Segmentation } \\
\text { Multilevel }\end{array}$ & $\begin{array}{l}\text { Not included in the analysis. This } \\
\text { category includes keywords that } \\
\text { are unlikely to affect recycling } \\
\text { behavior and that do not belong to } \\
\text { any other category. }\end{array}$ \\
\hline
\end{tabular}


research methods where not considered an important category to explain recycling behavior. In the 62 studies considered six different methods were used, and even though the survey method was far the most common one, there is nothing that speaks against the other methods as completely satisfactory.

\subsection{Background factors}

The most common background factors, age and gender, are debated if they have an impact on recycling behavior or not. In some studies, there are differences and in others there is not. Furthermore, some researchers have found that older people have a higher recycling partaking and for others it is the other way around, the same goes for gender [20]. However, age probably has an impact if we study the really old, when physical limitations increase, as these possibly affect recycling behavior [9]. Nevertheless, there are some background factors that seem to explain some differences in recycling behavior, such as social class and religion [21, 22]. However, even if some authors have found significant differences in what way exactly the studies have been limited and it is hard to draw any far-reaching conclusions. Solid waste recycling is predominantly an urban phenomenon [23], and hence "place-of-living" might be another background factor worth mentioning. However, this factor is generally disregarded in most research studies, or studies are only conducted in a single location. The global trends of increasingly older population, urbanization, and a growing middle-class, are challenges that might change the basic conditions for recycling.

\subsection{Communication and information}

Overall, the level of knowledge seems to have an influence on the propensity to recycle [10, 18]. Information can increase environmental awareness and ecological behavior; this is shown for example by Wandmacher et al. [24]. They reported an increase in recycling efficiency of about $15-25 \%$ due to new information labels [25]. Information appears to have two aspects; one theoretical and one practical. The theoretical aspect informs people about the benefits of recycling and its impact on the environment, and the practical communication informs people how and where they can recycle. Since the theoretical part of information facilitates the understanding of the bigger picture, it is possibly the basis for moral or natural incentives; see the Incentives section. The practical information on the other hand, tells the story of details, and will probably not affect any higher moral to recycle, but facilitate the actual doing. The two different aspects seem to affect differently. To recycle, the latter seem to be necessary, but the former less so $[9,26]$.

\subsection{Design}

The design of recycling facilities can have an impact on recycling behavior. In some cases, the physical design aids recycling behavior [27, 28], such as the introduction of curbside collection, sorting bins specially designed for indoor use to reduce the problems of confined recycling space, or recycling equipment designed for a specific environment, e.g. by using air-filled tires on recycling bins 
in construction sites to increase maneuverability. Design can also trigger the psychological willingness to recycle, for example, by adding a fun factor to recycling. There have been examples of bins painted like cows [29] and a bottle bank arcade machine: both increased waste and recycled material [30]. In the former example four waste bins were painted as cows with the advertising slogan "Feed the Cows". In the second example a bottle collection bin was remodeled to resemble an arcade machine. In other cases, designs are vital, for example, access location or access points are often placed at a level that prevents people with limited physical mobility such as elderly or disabled people from recycling [9]. Since the number of people over the age of 65 is expected to nearly triple between 2010 and 2050 to about 1.5 billion people, the need for design for the elderly seems to be urgent [31].

\subsection{Incentives}

Waste recycling is seldom considered to be an exciting task and it is fairly easy to cheat. To increase interest and recycling rates authorities and other stakeholders sometimes want to introduce incentives to motivate individuals to perform as favored. Incentives can be remunerative, moral, coercive or natural. The remunerative incentives are usually based on repayment when recycling (deposit systems) or decreased costs by volume- based waste fees (less waste, lower cost). Moral incentives occur when a certain choice is regarded as the right thing to do, it is right to recycle for the benefit of the environment or viewed as immoral when not performed. Coercive incentives are the risk of some sort of punishment for wrongdoing. Finally, natural incentives are things such as curiosity, mental or physical exercise, admiration, fear, anger, pain, joy, or the pursuit of truth, etc. The outcome of monetary incentives varies between different studies. Moral incentives seem to play a lesser role [26], and natural incentives have not been studied in depth, although joy or fun factors seem to have some influence as described above.

\section{Discussion}

Any attempt to clarify and explain why one person recycles and another does not, is certainly a complex task. However, the literature describes in different ways how recycling behavior is affected by different factors. Each factor can be seen as relying on both internal and external conditions. Take, for example, the case of fun design, where the design itself is an external factor, but the increased willingness to use it would rather be described as an internal natural incentive. In order to condense the findings of this study, the author proposes a model based on two aspects explaining recycling behavior; simplicity and motivation. It seems logical that if motivation is high and the task of recycling is simple, recycling rates would be high, and vice versa. The factors discussed earlier may affect one or both of these aspects. At first glance, it may be tempting to see motivation as a predominantly internal condition, while simplicity would be an external condition. However, this would oversimplify the picture and ignore internal aspects of simplicity and external aspects of motivation. For example, information affects 
simplicity in a rather obvious way; good information, e.g. a distinct sign or a wellwritten pamphlet will guide the recycler to perform correctly. After a few times the recycler knows how to behave and external information has become internal knowledge. The following two sections will further develop the concepts of simplicity and motivation.

\subsection{Simplicity}

Simplicity is how easy it is for a recycler to actually recycle waste. This is affected by factors such as the distance to recycling facilities, container design, time required, and knowledge about what and how to recycle. There are few people who strongly oppose recycling $[8,12,26]$ and most people are prepared to make small efforts to recycle, for example, they are prepared to spend time at home on recycling or having extra bins in their homes or gardens [32]. For any society or entity that wants to initiate recycling routines, the first step must be to satisfy the need of how and where [33-36]. This is not always as simple or clear as it seems; an article by Howenstine [8] describes that in a survey with students from Illinois University, three out of four respondents did not know the location of a single drop-off site, although there had been one across the street from the university for many years.

A short distance to bins is obviously a matter of simplicity, which is shown in several articles and many countries have introduced curbside collections, which have proven effective. However, as González-Torre and Adenso-Díaz [37] also point out, if the common drop-off site is near enough, the benefits of curbside collection decrease. The design of bins can also have an impact, especially for groups with physical limitations, such as older people. For them, the access point for putting waste into a bin might be at a critical height or they might need easier wheelie bins for curbside schemes [9]. This is something that must be taken into account since the world population of older people is increasing. An estimation by Wolfgang Fengler of the World Bank is that the number of 60-79-year-olds will increase by 1.6 billion by 2050 [38].

Changes in recycling fractions and lack of knowledge of how some materials or items should be recycled can also prevent people from recycling [33, 39]. Practical, adapted information is important and if not present, can be something that even works against recycling [40]. Information about how to recycle should ideally use different designs, texts, pictures, illustrations, etc. for the convenience of the individual, since people process information in various ways [41, 42]. It is also evident that if municipalities want to increase their recycling rates, they must plan long-term communication campaigns to encourage and maintain the recyclers in the long run [42]. New designs can also help to reduce the need for detailed information, such as the reverse vending machine, where people do not need to separate cans and bottles [43].

\subsection{Motivation}

Motivation can be both internal and external. Internal motivators include environmental values beliefs and attitudes, for example, environmental knowledge, anticipated guilt or altruism. External motivators are all the reasons 
that externally affect recycling attitudes, intentions, and behaviors, such as monetary incentives, community pressure or laws and regulations.

A general awareness of the positive environmental aspects of recycling seems to be widespread at least in a theoretical perspective [8, 22]. This general knowledge does not seem to be enough to make people more motivated to recycle $[22,44]$ though some researchers have found significant, albeit weak effects [45]. It seems the knowledge has to be more specific of how recycling affect the environment and an understanding or presumption that the recycling execution has a positive effect regardless how small. Another explanation to the differences in behavior in the group that have a general environmental concern is more indirect. Elgaaied [46] has found that anticipated guilt seems to play a major role in people's intentions to recycle. Anticipated guilt was also found to be a link between facilitating conditions and intentions to recycle, i.e. the better the facilities, the guiltier the people would feel about not recycling.

Environmental laws and regulations seem to have a major impact on people's behavior. People tend to see environmental issues as moral issues, and both law and morality serve to channel our behavior [47]. Both law and morality have their different incentive systems, where law mainly acts by threat of sanctions if we disobey legal rules, and morality works by providing the individual who acts badly with a bad conscience or guilt, and good acts may result in virtuous feelings or praise. This works optimally if the two patterns of law and morality are in alignment with another, which they seem to be in the mind of most people in the environmental arena [47].

Establishing whether monetary incentives are effective or not seems to differ between different researchers. There are many who do not consider it very important $[11,48]$ and others who believe it to be an effective way to deal with recycling. Saphores et al. [49] for example, favor a deposit system for e-waste.

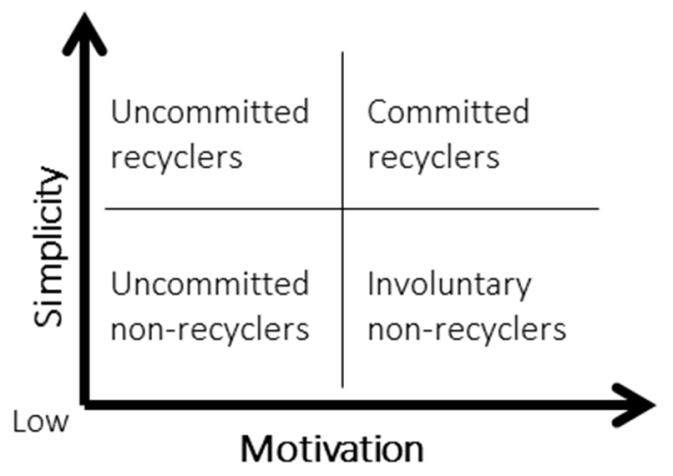

Figure 1: Recycling behavior model.

Based on the aspects of simplicity and motivation, the characteristics of four different recycling behavior can be distinguished and explained. These four recycling characters can be described as: 
- Uncommitted non-recyclers;

- Uncommitted recyclers;

- Committed recyclers;

- Involuntary non-recyclers.

The uncommitted non-recyclers and the committed recyclers are, as groups, easy to understand, they follow their beliefs or lack of beliefs and behave accordingly. The other two groups are different. The involuntary non-recyclers are a group of people who believe in recycling but do not recycle, often because of a lack of recycling facilities or perceived lack of vital parts of it, such as suitable recycling instructions [46]. The uncommitted recyclers on the other hand perform the task without any strong beliefs in recycling. There is a tendency (at least in the developed world) that recycling has become such a common practice and so easy to perform that it is almost habitual [26].

Recycling seems to be dependent on simplicity and motivation, and high recycling rates should be achievable if motivation is high and the conditions to execute the task are simple. But as figure 1 shows, simplicity is vital for recycling whereas motivation seems to be more of a nice-to-have feature. Many studies have shown that individuals with the same level of motivation behave differently due to the simplicity of the task [46]. It has also been found that regardless of attitudes, people recycle if the conditions to do so are simple enough [26].

Motivation should not be ruled out, however, as in all human activities motivation can induce actions to bring about the facilities or knowledge needed to perform the desired task [10]. This is regardless of whether it is to find the nearest bring site, lobby for curbside collection or build your own compost heap. Uncommitted recyclers, on the other hand, will probably not be motivated enough to adapt very quickly to change, or the slightest inconvenience in recycling facilities will result in decreased recycling rates [40].

To increase recycling rates, different courses of action must be used, depending on what group is addressed, but for all groups, having a recycling infrastructure is a must [9]. Involuntary non-recyclers probably do not need as advanced system to initiate recycling behavior as uncommitted non-recyclers. For the latter group it would need to be almost as simple to recycle as not to recycle [50] since it is very rare that people are directly opposed to recycling and make an extra effort not to recycle $[12,26]$. Uncommitted non-recyclers are possibly not open to much information about the benefits of recycling [9]; for this group it is inevitably better to get the system in place and thus make them begin to recycle. To give uncommitted recyclers more information about the benefits of recycling might be more successful due to positive reinforcement. They are already engaged in recycling behavior, and if this behavior gets them some positive feed-back, then they are more likely to engage in that same behavior again [4]. They might even end up as committed recyclers one day. Positive reinforcement is probably also be an effective way for committed recyclers to maintain their motivation and recycling behavior [22]. 


\section{Conclusions}

In the simplest of worlds there are detailed directions on how to act in any given recycling situation However, this is seldom the case and there is no universal method to stimulate recycling [8]. The conditions around recycling are dependent on external and internal conditions that differ between places and people, but the general characteristics of a recycling system seem to follow a pattern regardless of the people involved. So even if it is not possible to provide specific instructions in a given recycling situation, there are some important principles that should be used when recycling situations are introduced or developed.

First of all, most people consider recycling to be a low priority task [9] and tasks with lower priority have a tendency to not be performed if the task is perceived as inconvenient. Therefore, it is important to design recycling facilities as close to the recycler as possible and facilities should be equipped to work in a given situation, for example, with lower access points. Secondly, it is important to have knowledge about how and where to recycle; uncommitted recyclers or nonrecyclers tend to have less or obsolete information that prevents them from recycling. Even if motivation and understanding are in place, without knowledge of how to recycle, it still does not work [33]. Finally, a contributing step is to establish a deeper understanding of the environment and the impact of recycling to gain or maintain a general level of motivation, which might further increase recycling.

\section{References}

[1] Marans, R.W. and Y.-J. Lee, Linking recycling behavior to waste management planning: A case study of office workers in Taiwan. Landscape and Urban Planning, 1993 (26): pp. 203-215.

[2] Hardin, G., The Tragedy of the Commons. Science, 1968 (162(3859)): pp. 1243-1248.

[3] Ostrom, E., et al., Revisiting the Commons: Local Lessons, Global Challenges Science, 1999 284(5412): pp. 278-282.

[4] Tabernero, C., et al., A multilevel perspective to explain recycling behaviour in communities. Journal of Environmental Management, 2015 (159): pp. 192-201.

[5] Hoornweg, D. and P. Bhada-Tata, What a Waste: A Global Review of Solid Waste Management. Urban Development Series, 2012 (15).

[6] Dai, Y.C., et al., Why doorstepping can increase household waste recycling. Resources Conservation \& Recycling, 2015 (102): pp. 9-19.

[7] Tai, J., et al., Municipal solid waste source separated collection in China: A comparative analysis. Waste Management, 2011 (31): pp. 1673-1682.

[8] Howenstine, E., Market Segmentation for Recycling. Environment and Behavior, 1993. 25(1): pp. 86-102.

[9] Langley, J., Is Green a Grey Area? Sustainability and Inclusivity: Recycling and the Ageing Population. The Design Journal, 2012. 15(1): pp. 33-56. 
[10] Vining, J. and A. Ebreo, What Makes a Recycler? A Comparision of Recyclers and Nonrecyclers. Environment and Behavior, 1990. 22(1): pp. 55-73.

[11] Wagner, T.P., Examining the concept of convenient collection; An application to extended producer responsibility and product stewardship frameworks. Waste Management, 2013 (33): pp. 499-507.

[12] Miafodzyeva, S., N. Brandt, and M. Olsson, Motivation recycling: prerecycling case study in Minsk, Belarus. Waste Management \& Research, 2010 (28): pp. 340-346.

[13] DiCenso, A., G. Guyatt, and D. Ciliska, Evidence-based Nursing: A Guide to Clinical Practice. 2005: Elsevier Health Sciences, St Louis, Mosby.

[14] Forsberg, C. and Y. Wengström, Att göra systematiska litteraturstudier: värdering, analys och presentation av omvårdnadsforskning. 2008, Stockholm: Natur \& Kultur.

[15] Hearn, W.S., et al., Estimation of tag reporting rates in age-structured multicomponent fisheries where one component has observers. Canadian Journal of Fisheries and Aquatic Sciences, 1999 (56): pp. 1255-1265.

[16] Bryman, A. and E. Bell, Business Research Methods. 2007, Oxford University Press Inc., New York.

[17] Wilson, D.C., et al., Business waste prevention: a review of the evidence. Waste Management \& Research, 2012. 30(9): pp. 17-28.

[18] Hornik, J., et al., Determinants of recycling behavior: A synthesis of research results. Journal of Socio-Economics, 1995 (24): pp. 105-127.

[19] Friberg, F., Dags för uppsats - vägledning för litteraturbaserade examensarbeten. 2006, Lund: Studentlitteratur.

[20] Gifford, R., Environmental Psychology: Principles and Practice. 4th ed. 2007, Colville: WA: Optimal Books.

[21] Mohamad, Z.F., et al., The role of religious community in recycling: Empicical insights from Malaysia. Resources, Coservation and Recycling, 2012 (58): pp. 143-151.

[22] Iyver, E.S. and R.K. Kashyap, Consumer recycling: Role of incentives, information, and social class. Journal of Consumer Behaviour, 2007(6): pp. 32-47.

[23] Hoornweg, D., P. Bhada-Tata, and C. Kennedy, Waste production must peak this century. Nature, 2013. 502: pp. 615-617.

[24] Wandmacher, S., et al., Erfolge und Grenzen von Interventionsmaßnahmen zur Verbesserung des Entsorgungssystems in der Klinikum Wuppertal $\mathrm{GmbH}$ [Successes and Limits of Intervention Measures to Improve the Waste Management System in the Klinikum Wuppertal GmbH], ed. J. Vogt and M. Kastner. 2002: Herdecke: MAORI-Verlag.

[25] Vogt, J. and K.R.A. Nunes, Recycling behaviour in healthcare: waste handling at work. Ergonomica, 2014. 57(4): pp. 525-535.

[26] Hergatt Huffman, A., et al., When do recycling attitudes predict recycling? An investigation of self-reported versus observed behavior. Journal of Environmental Psychology, 2014 (38): pp. 262-270. 
[27] Jensen, P. and C.W. Nielsen, The determinants of household recycling: A material specific analysis of recycling program features and unit pricing. Journal of Environmental Economics and Management, 2001. 45(2): pp. 294-318.

[28] Corral-Verdugo, V., et al., Residential Water Consumption, Motivation for Conserving Water and the Continuing Tragedy of the Commons. Environmental Management, 2002. 30(4): pp. 527-535.

[29] Cowbin-Pilot-Report, A report on the Cowbins ${ }^{\mathrm{TM}}$ recycling promotion project in New Cross Gate, Lewisham 2006, The Onyx Environmental Trust: New Cross Gate, Public Bring Site, Cowbin ${ }^{\mathrm{TM}}$ Pilot - Report.

[30] thefuntheory.com.

[31] NIA. https:/www.nia.nih.gov/research/publication/global-health-andaging/humanitys-aging. 2016.

[32] Byrne, S. and B. O'Regan, Attitudes and actions towards recycling behaviours in the Limerick, Ireland region. Resources, Conservation and Recycling, 2014 (87): pp. 89-96.

[33] Prestin, A. and K.E. Pearce, We care a lot: Formative research for a social marketing campaign to promote school-based recycling. Resources, Conservation and Recycling, 2010 (54): pp. 1017-1026.

[34] Aini, M.S., et al., Practices, attitudes and motives for domestic waste recycling. International Journal of Sustainable Development \& World Ecology, 2002 (9): pp. 232-238.

[35] Zen, I.S., Z.Z. Noor, and R.O. Yusuf, The profiles of household solid waste recyclers and non-recyclers in Kuala Lumpur, Malaysia. Habitat International, 2014 (42): pp. 83-89.

[36] Gamba, R.J. and S. Oskamp, Factors Influencing Community Residents' Participation in Commingled Curbside Recycling Programs. Environment and Behavior, 1994. 26 (5): pp. 587-612.

[37] González-Torre, P.L. and P. Adenso-Díaz, Influence of distance on the motivation and frequency of household recycling. Waste Management, 2005 (25): pp. 15-23.

[38] Fengler, W. The End of the Population Pyramid. 2014.

[39] Scott, D., Equal Opportunity, Unequal Results: Determinants of Household Recycling Intensity. Environment and Behavior, 1999. 31(2): pp. 267-290.

[40] Johansson, K., Effective and Efficient Waste Sorting in Construction Sites, in NOFOMA. 2015: Molde.

[41] Vicente, P. and E. Reis, Segmenting households according to recycling attitudes in a Portuguese urban area. Resources, Conservation and Recycling, 2007 (52): pp. 1-12.

[42] Mee, N., A Communications Strategy for Kerbside Recycling. Journal of Marketing Communications, 2005. 11(4): pp. 297-308.

[43] Returpack. http://www.mynewsdesk.com/se/ab_svenska_returpack/ pressreleases/aennu-enklare-att-panta-mera-1257178. 2015.

[44] Oom Do Valle, P., et al., Behavioral Determinants of Household Recycling Paricipation: The Portuguese Case. Environment and Behavior, 2004. 36(4): pp. 505-540. 
[45] Abbott, A., S. Nandeibam, and L. O'Shea, Recycling: Social norms and warm-glow revisited. Ecological Economics, 2013 (90): pp. 10-18.

[46] Elgaaied, L., Exploring the role of anticipated guilt on pro-environmental behavior - a suggested typology of residents in France based on their recycling patterns. Journal of Consumer Marketing, 2012 (29/5): pp. 369377.

[47] Shavell, S., Law versus Morality of Regulators of Conduct. American Law and Economics Association, 2002.

[48] Hage, O., P. Söderholm, and C. Berglund, Norms and economic motivation in household recycling: Empirical evidence from Sweden. Resources, Conservation and Recycling, 2009 (53): pp. 155-165.

[49] Saphores, J.-D.M., O.A. Ogunseitanc, and A.A. Shapiro, Willingness to engage in a pro-environmental behavior: An analysis of e-waste recycling based on a national survey of U.S. households. Resources, Conservation and Recycling, 2012 (60): pp. 49-63.

[50] Poferl, A., K. Schilling, and K.W. Brand, Environmental awareness and everyday actions. An empirical study socio-cultural orientations. Leske Budrich, Opladen, 1997. 